\title{
Analysison Students' Learning Habits: Identifyingthe Contributory Factorsof Learning Duringthe Covid-19 PandemicUsing Radial Basis Function (RBF)
}

\author{
Nur Nabilah Abu Mangshor ${ }^{1}$, Shafaf Ibrahim ${ }^{2}$, Nurbaity Sabri ${ }^{3}$, Hazwa Hanim Mohamed \\ Hamzah $^{4}$, Saadi Ahmad Kamaruddin ${ }^{5}$ \\ ${ }^{1234}$ Faculty of Computer and Mathematical Sciences, Universiti Teknologi MARA Cawangan Melaka (Jasin \\ Campus), 77300 Merlimau, Melaka, MALAYSIA \\ ${ }^{5}$ School of Qualitative Sciences, College of Arts \& Sciences, Universiti Utara Malaysia, 06100, UUM Sintok, \\ Kedah, MALAYSIA \\ nurnabilah@uitm.edu.my ${ }^{1}$
}

Article History: Received: 11 January 2021; Accepted: 27 February 2021; Published online: 5 April 2021

\begin{abstract}
The Artificial Neural Network (ANN) is an Artificial Intelligence technique that offer many benefits including the ability to process a vast amount of data, the ability to learn from experiences, and the good generalization capability. It was invented based on the concept of imitation of the human brain and built up of nodes that are like human neurons. The Radial Basis Function (RBF) is one of the established types of ANN. Considering the advantages and great performance of the RBF, this study aims to investigate the contributory factors of students' learning habits during the Coronavirus Disease 2019 (or known as COVID-19) pandemic using RBF. Responses from a total of 420 respondents were collected from Vietnamese students' learning habits during the COVID-19 pandemic dataset that was established from the questionnaires distributed in the period of 7th February 2020 to 28th February 2020. Fifteen independent variables were used as the input for the RBF network which is based on the 15-9-1 structure. Based on the experiment conducted, the implementation of the RBF model was found to be fair and effective with the small number of Sum of Square Error (SSE) and Relative Error (RE) produced. It could also be concluded that the most contributing factor of students' learning habits during the COVID-19 pandemic is the learning hours per day for self-learning before the pandemic.
\end{abstract}

Keywords: Covid-19, learning habits, Artificial Neural Network (ANN), Radial Basis Function (RBF).

\section{Introduction}

Online learning has started to grow in many educational institutions due to its flexibility, mobility, and effectiveness since the early stage of the 21 st century [1-3]. Also, online learning or e-learning is not something new in higher educational institutions as this approach has been implemented in universities' distance learning process. However, recently, online learning has turned out to be an essential activity among students due to the closure of educational institutions due to the COVID-19 pandemic, thus, possible opportunities related to online learning have been explored [4]. Recently, people all over the world are struggling to cope with the new normal since COVID-19hits. Hence, the implementation of normal learning has shifted from the traditional physical classroom into a virtual classroom [5]. Due to that, enormous educational institutions worldwide have conducted online and resulting direction towards studying student's learning habits.

Students learning habits are very essentials as they affects student's attitude, knowledge, and performance [6]. It is mentioned in [7] that learning habits encompass mental, physiological, natural habits, and the preferred ways of absorbing, processing, and retaining new knowledge and skills. Learning habits reflect student's usual act of studying and serve to direct the learner's cognitive processes during learning [2]. This process includes activities that deal with time management, goal setting, appropriate study environment, using appropriate notetaking strategies, choosing main ideas, and organization [2][8]. Studies in [1][2] mentioned that there is a positive correlation between learning habits and learner performance. Hence, it is very important to analyse student's learning habits as it is one of the main factors affecting their performance in learning.

The Artificial Neural Network (henceforth, ANN) is an Artificial Intelligence technique that has many benefits including the ability to process a vast amount of data, the ability to learn from experiences, and the good generalization capability [9]. Initially, ANN was invented based on the concept of imitation of the human brain [10]. ANN is a built up of nodes that are like human neurons. All these nodes are interconnected to one another and build up a network. One of the established types of the neural network is based on the Radial Basis Function (RBF) network.

There are many available works related to the RBF network model. For instance, RBF is vastly applied in the engineering sector and it produces promising results. Among of the examples are the application of RBF modelling submerges breakwaters [11], monitoring tunnel ventilating system [12], estimating reinforce building's seismic damage level [13], and wind energy conversion system [14]. Meanwhile, for the prediction task, RBF is applied in estimating the chemical structure of aluminium foam [15], predicting factors that 
contribute to COVID-19'sdeath and spread [16-17], predicting and recognizing human activity [18], and as well in predicting construction cost [19].

Considering the advantages and great performance of Radial Basis Function (RBF) ANN, this study aims to investigate the contributory factors of students' learning habits during the COVID-19 pandemic. The implementation of RBF is expected to give insights and understandings on the factors that contribute to online learning habits among students. The structure of this paper is as the following: Section 2 discusses the data background and followed by Section 3 which elaborates on the methodology. Next, results and discussions are presented in Section 4 while Section 5 is the conclusion.

\section{Data background}

A dataset of of Vietnamese students' learning habits during the COVID-19 pandemic [20] was retrieved from the Research Gate's open source. This dataset was established from the questionnaires distributed in the period of 7th February 2020 to 28th February 2020. It comprised of three major groups of questions which are (1) student's demographic, (2) student's learning habits, and (3) student's perception of self-learning during the school closure. This dataset was composed of 460 responses from the secondary students in grades 6-12. However, only 420 data were valid after the process of data cleaning. The descriptive statistics of the dataset is illustrated in Table 1 as follows.

Table 1: Descriptive Statistics [20]

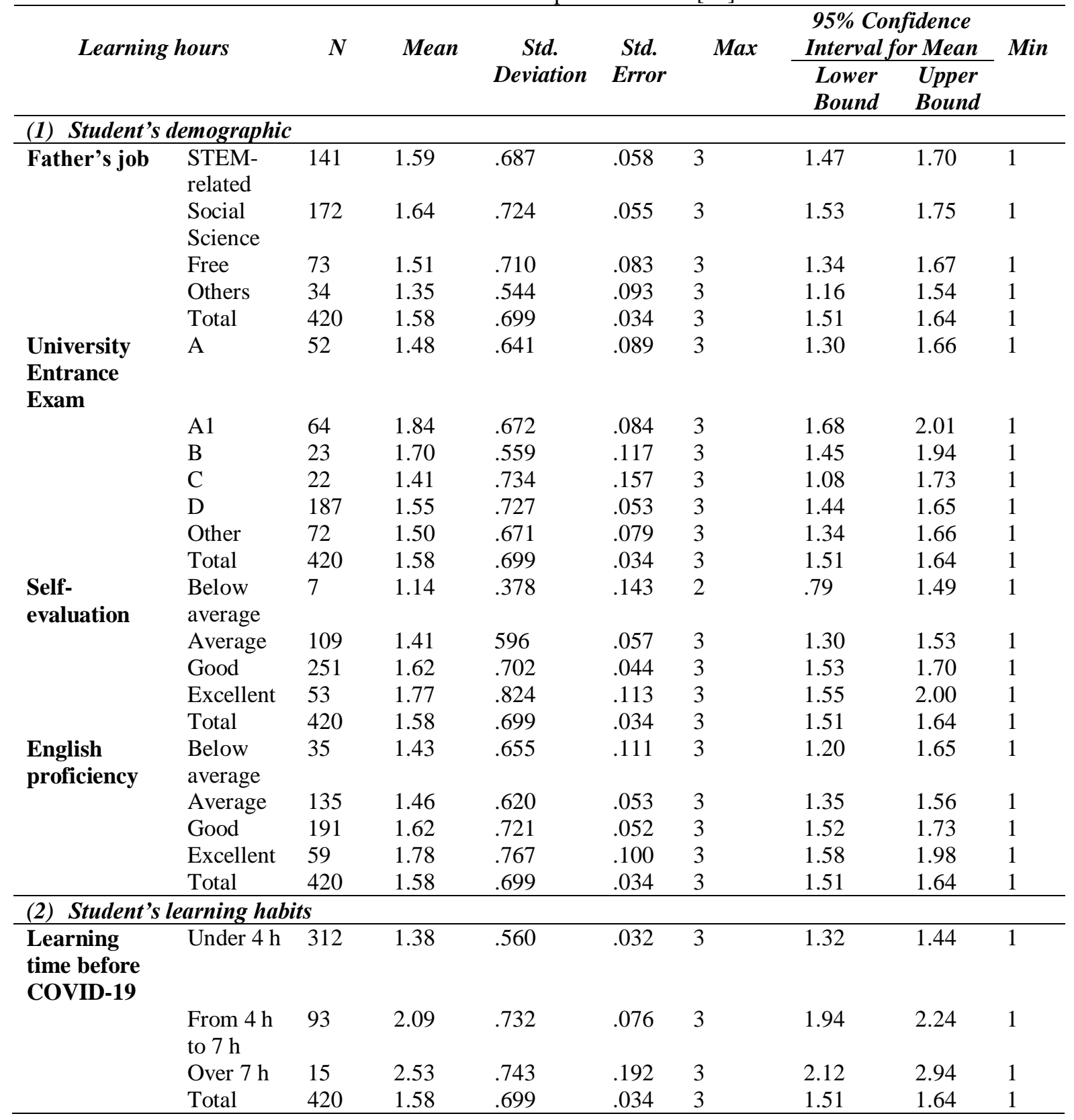


Nur Nabilah Abu Mangshor ${ }^{1}$, Shafaf Ibrahim², Nurbaity Sabri ${ }^{3}$, Hazwa Hanim Mohamed Hamzah ${ }^{4}$, Saadi Ahmad Kamaruddin ${ }^{5}$

\begin{tabular}{|c|c|c|c|c|c|c|c|}
\hline \multicolumn{8}{|c|}{ (3) Student's perceptions of self-learning during the school closure } \\
\hline & \multirow[t]{2}{*}{$N$} & \multirow[t]{2}{*}{ Range } & \multirow[t]{2}{*}{ Min } & \multirow[t]{2}{*}{$\operatorname{Max}$} & \multicolumn{2}{|c|}{ Mean } & \multirow{2}{*}{$\begin{array}{c}\text { Std. } \\
\text { Deviation }\end{array}$} \\
\hline & & & & & Statistics & Std. Error & \\
\hline $\begin{array}{l}\text { I can ensure my learning } \\
\text { progress }\end{array}$ & 420 & 4 & 1 & 5 & 3.90 & .047 & .965 \\
\hline $\begin{array}{l}\text { I can maintain my learning } \\
\text { habits }\end{array}$ & 420 & 4 & 1 & 5 & 3.88 & .045 & .926 \\
\hline $\begin{array}{l}\text { My parents show me it is } \\
\text { necessary }\end{array}$ & 420 & 4 & 1 & 5 & 3.73 & .050 & 1.019 \\
\hline $\begin{array}{l}\text { I am motivated for self- } \\
\text { learning }\end{array}$ & 420 & 4 & 1 & 5 & 3.44 & .049 & .998 \\
\hline $\begin{array}{l}\text { I have good concentration } \\
\text { skills }\end{array}$ & 420 & 4 & 1 & 5 & 3.36 & .047 & .970 \\
\hline $\begin{array}{l}\text { I have support from my } \\
\text { family }\end{array}$ & 420 & 4 & 1 & 5 & 3.35 & .053 & 1.090 \\
\hline $\begin{array}{l}\text { I have an effective learning } \\
\text { environment }\end{array}$ & 420 & 4 & 1 & 5 & 3.55 & .050 & 1.034 \\
\hline $\begin{array}{l}\text { I can define my daily } \\
\text { learning objectives }\end{array}$ & 420 & 4 & 1 & 5 & 3.44 & .050 & 1.017 \\
\hline $\begin{array}{l}\text { I have various learning } \\
\text { resources }\end{array}$ & 420 & 4 & 1 & 5 & 3.66 & .048 & .983 \\
\hline $\begin{array}{l}\text { I communicate and } \\
\text { collaborate with my } \\
\text { friends about learning }\end{array}$ & 420 & 4 & 1 & 5 & 3.21 & 055 & 1.129 \\
\hline
\end{tabular}

\section{Research methodology}

This section discusses the methodology used in this study that aims to assess the performance of the RBF network in investigating the contributory factors of students' learning habits during the COVID-19 pandemic.

A. Radial Basis Function (RBF) Network

The RBF network is a feed-forward neural network type. It is built of three different layers which are the input layer, the hidden layer, and the output layer [11]. The representation of input pattern used in RBF network is based on the middle layer given with a set of input units. The use of the activation functions at this middle layer is important for the purpose to characterize each of the input units used in the network.

RBF is highly successful in function approximation and pattern recognition [21]. Moreover, it is also known that the RBF structure offers a simple layout, rapid convergence speed and more important is to be able to perform universal approximation [11][12][15]. The RBF network is widely used due to its advantages such as excellent generalization, easy structure, high input noise tolerance and online learning capabilities [16][17]. An example of a basic structure of RBF with one hidden layer is demonstrated in Fig 1.

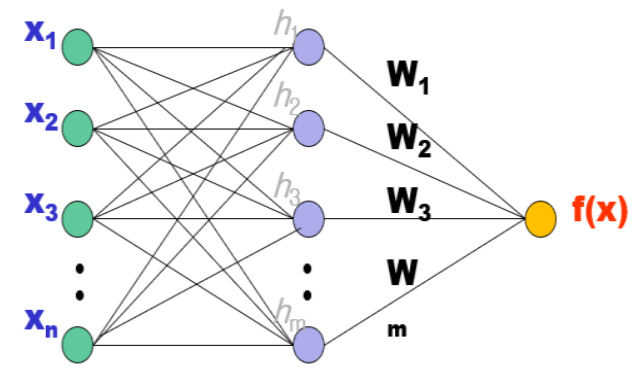

Figure 1: RBF network with one hidden layer [22]

The radial basis function used in the network depends on the strategy of the network itself. The approximation function with linear combination of Radial Basis function is expressed as in Equation 1.

$$
\mathrm{F}(\mathrm{x})=\mathrm{S} \quad \mathrm{w}_{\mathrm{i}} \mathrm{h}(\mathrm{x})
$$

Where $(h x)$ is mostly the Gaussian functions. The RBF neuron activation function is slightly different and is typically written as in Equation 2. 


$$
\begin{aligned}
& f(x)=\sum w_{j} h_{j}(x) \\
& h_{j}(x)=\exp \left(-\left(x-c_{j}\right)^{2} / r_{j}^{2}\right)
\end{aligned}
$$

Where $c j$ is the centre of a region and $r j$ is the width of the receptive field.

\section{Result and analysis}

This section discusses the results obtained from the experiment conducted. The dataset dataset of the Vietnamese students was run using SPSS 13. The case processing summary for RBF is displayed in Table 2.

\begin{tabular}{lccc}
\multicolumn{3}{l}{ Table 2: Case Processing Summary for RBF Mode } \\
\hline & & $\boldsymbol{N}$ & Percent \\
\hline Sample & Training & 304 & $72.4 \%$ \\
& Testing & 116 & $27.6 \%$ \\
Valid & & 420 & $100.0 \%$ \\
Excluded & 0 & \\
Total & & 420 & \\
\hline
\end{tabular}

Based on Table 2, the dataset used in this study was divided into two groups; which are training and testing. The training set for RBF is $72.4 \%$ (304/420) and the testing set is $27.6 \%$ (116/420). The overall data from the dataset is $\mathrm{N}=420$ and there is no excluded data reported.

There were fifteen covariates used in the network which are fa_job, exam, Self_evaluation, English, Lh_before_Cov, nec_prog, nec_habit, nec_parent, eff_moti, eff_con eff_supp, eff_env, eff_obj, eff_resource, and eff_friend. Table 3 shows the descriptions of the covariates used in this study.

\begin{tabular}{|c|c|c|}
\hline $\begin{array}{l}\text { Input } \\
\text { layer }\end{array}$ & Covariates & Descriptions \\
\hline 1 & $f a \_j o b$ & What is your father's job? \\
\hline 2 & exam & $\begin{array}{l}\text { What subject group do you intend to } \\
\text { take for the university entrance exam? }\end{array}$ \\
\hline 3 & Self_evaluation & $\begin{array}{l}\text { How do you evaluate your } \\
\text { performance, regarding your selected } \\
\text { subject group? }\end{array}$ \\
\hline 4 & English & $\begin{array}{l}\text { How do you evaluate your English } \\
\text { capability? }\end{array}$ \\
\hline 5 & Lh_before_Cov & $\begin{array}{l}\text { Before COVID-19, how many hours } \\
\text { did you spend per day for self-learning? }\end{array}$ \\
\hline 6 & nec_prog & I can assure my learning progress \\
\hline 7 & nec_habit & I can maintain my learning habit \\
\hline 8 & nec_parent & My parents show me it is necessary \\
\hline 9 & eff_moti & I am motivated for self-learning \\
\hline 10 & eff_con & I have proper concentration skills \\
\hline 11 & eff_supp & I have support from my family \\
\hline 12 & eff_env & $\begin{array}{l}\text { I have an effective learning } \\
\text { environment }\end{array}$ \\
\hline 13 & eff_obj & $\begin{array}{l}\text { I can define my daily learning } \\
\text { objectives }\end{array}$ \\
\hline 14 & eff_resource & I have various learning resources \\
\hline 15 & eff_friend & $\begin{array}{l}\text { I communicate and collaborate with my } \\
\text { friends about learning }\end{array}$ \\
\hline
\end{tabular}

Table 3: Covariates' Descriptions

These fifteen covariates acted as the input for the RBF network. The activation function used in the network is Softmax and there is one dependent variable which is Lh_in_Cov. To simplify the architecture, it could be addressed as the 15-9-1 RBF network architecture as portrayed in Fig 2. 


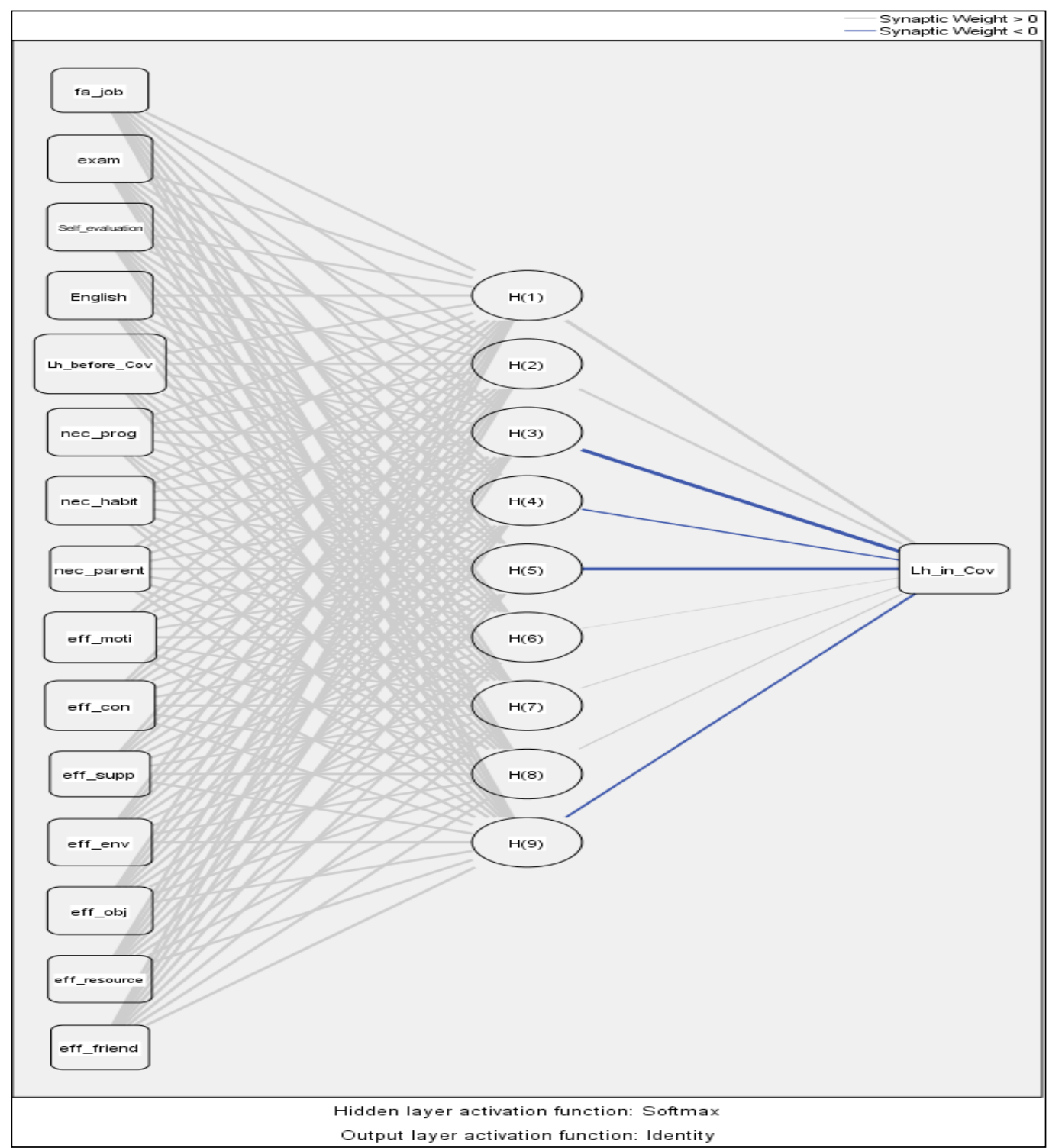

Figure 2: RBF Network Architecture

Based on the illustration of the RBF network architecture in Fig 2, this network is composed of 15 inputs with one hidden layer with 9 nodes. Softmax is used as the hidden layer activation function. Hence, the target output of this network is the learning hours during COVID-19 (Lh_in_Cov). The identity (purelin) function is used as the activation function from the hidden layer to the output layer and the default error function applied is the sum of squares (SSE). SSE is the sum of differences between each observation group mean, and it is used to indicate the variation within a cluster. Hence, it can be concluded that the smaller the SSE, the lesser the variation between the clusters.

To simplify the configuration of the network, it is addresses as the 15-9-1 RBF network structure. Consequently, Table 4 tabulates a summary from the RBF network while Table 5 demonstrates the independent variables' importance.

Table 4: RBF Model Summary

\begin{tabular}{ccccc}
\hline & Training & \multicolumn{2}{c}{ Testing } \\
\hline $\begin{array}{c}\text { Sum of Squares } \\
\text { Error }\end{array}$ & Relative Error & Training Time & $\begin{array}{c}\text { Sum of Squares } \\
\text { Error }\end{array}$ & Relative Error \\
\hline 121.054 & & & $43.037^{\text {a }}$ & .630 \\
\hline
\end{tabular}

Dependent Variable: Lh_in_Cov 
a. The number of hidden units is determined by the testing data criterion: The "best" number of hidden units is the one that yields the smallest error in the testing data.

Table 5: Independent Variables' Importance

\begin{tabular}{lll}
\hline \multicolumn{1}{c}{ Variables } & Importance & $\begin{array}{l}\text { Normalized } \\
\text { Importance }\end{array}$ \\
\hline $\begin{array}{l}\text { What is your father's job? } \\
\text { What subject groups do you intend to take for }\end{array}$ & .032 & $19.8 \%$ \\
the university entrance exam? & .063 & $38.9 \%$ \\
$\begin{array}{l}\text { How do you evaluate your performance } \\
\text { regarding your selected subject group? }\end{array}$ & .065 & $40.5 \%$ \\
How do you evaluate your English & & \\
capability? & $\mathbf{. 0 6 5}$ & $\mathbf{4 0 . 7 \%}$ \\
Before COVID-19, how many hours did you &. $\mathbf{1 6 1}$ & $\mathbf{1 0 0 . 0 \%}$ \\
spend per day for self-learning? & .064 & $39.8 \%$ \\
I can assure my learning progress & $\mathbf{. 0 7 2}$ & $\mathbf{4 4 . 7 \%}$ \\
I can maintain my learning habit & .044 & $27.7 \%$ \\
My parents show me it is necessary & $\mathbf{. 0 8 8}$ & $\mathbf{5 4 . 9 \%}$ \\
I am motivated for self-learning & $\mathbf{. 0 8 1}$ & $\mathbf{5 0 . 5 \%}$ \\
I have proper concentration skills & .045 & $28.1 \%$ \\
I have support from my family & .058 & $36.4 \%$ \\
I have an effective learning environment & .064 & $39.5 \%$ \\
I can define my daily learning objectives & .059 & $36.8 \%$ \\
I have various learning resources & .038 & $23.4 \%$ \\
I communicate and collaborate with my friends & & \\
about learning & &
\end{tabular}

Table 5 tabulates the independent variables' importance for the RBF network constructed in this study. It is stated that the five most influential factors based in this study are Lh_before_Cov (100), eff_moti (54.9), eff_con (50.5), nec_habit (44.7), and English (40.7). Fig 3 portrays the normalized importance of the independence variables in the graph representation.

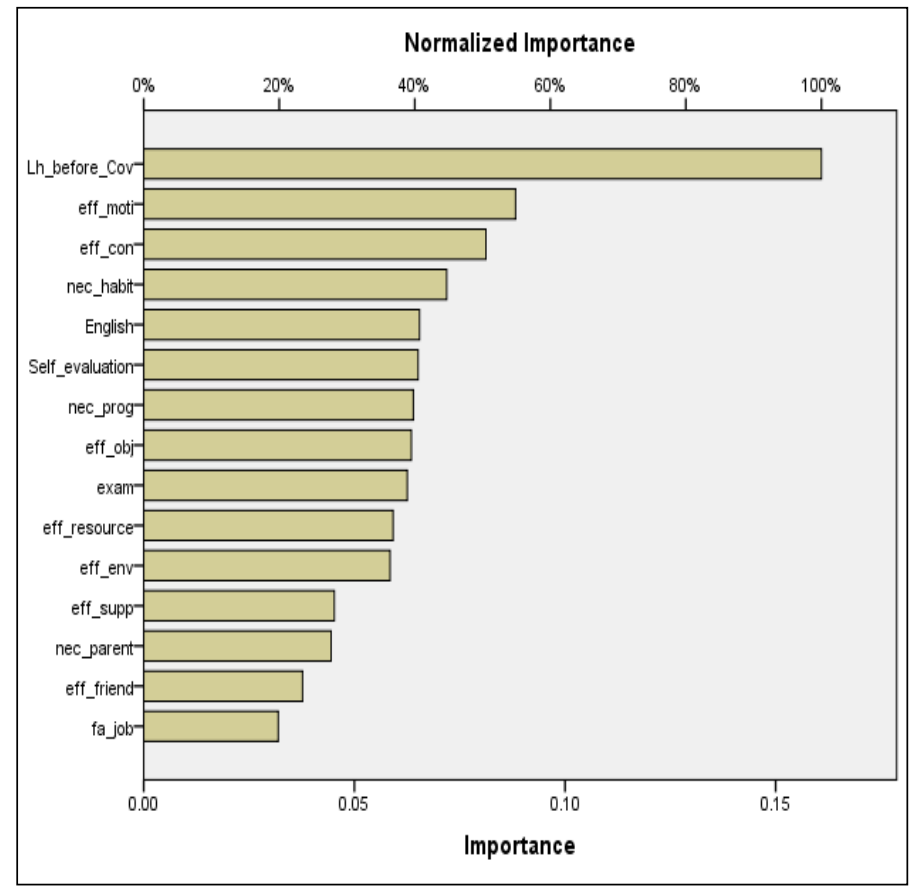

Figure 3: RBF Network Architecture

As previously mentioned, the performance evaluation was conducted on the developed RBF network model using the Sum of Square Error (SSE) and Relative Error (RE). Table 6 and Table 7 demonstrate the SSE and RE for the RBF network model, respectively. 
Table 6: SSE of ANN RBF Model

\begin{tabular}{lll}
\hline \multirow{2}{*}{$\begin{array}{l}\text { Rescaling of } \\
\text { Covariates }\end{array}$} & $\begin{array}{l}\text { Radial Basis Neural Network Activation Function } \\
\text { for Hidden Layer }\end{array}$ \\
\cline { 2 - 3 } & $\begin{array}{l}\text { Normalized Radial Basis } \\
\text { Function }\end{array}$ & $\begin{array}{l}\text { Ordinary Radial Basis } \\
\text { Function }\end{array}$ \\
\hline $\begin{array}{l}\text { Standardized } \\
\text { Normalized }\end{array}$ & $\mathbf{4 3 . 0 3 7}^{\mathrm{a}}$ & $58.425^{\mathrm{a}}$ \\
Adjusted & $56.313^{\mathrm{a}}$ & $\mathbf{4 0 . 3 1 8}^{\mathrm{a}}$ \\
Normalized & $54.092^{\mathrm{a}}$ & $52.350^{\mathrm{a}}$ \\
None & $53.056^{\mathrm{a}}$ & $69.189^{\mathrm{a}}$ \\
\hline
\end{tabular}

Based on the SSE results tabulated in Table 6, it can be observed that the Standardized rescaling method produced using the Normalized Radial Basis Function is lower than the Ordinary Radial Basis Function. However, in the Normalized rescaling method, the Ordinary Radial Basis Function achieved 40.318, as compared to the Normalized Radial Basis Function.

Next, for RE, the Normalized Radial Basis Function achieved 0.630 and 0.893 for the Standardized and Normalized rescaling factors, respectively. For the Ordinary Radial Basis Function, the Standardized and Normalized scaling factors obtained are 0.872 and 0.898 , respectively. Hence, it can be concluded that the RBF model is stable for both Normalized Radial Basis Function and Ordinary Radial Basis Function. In addition, these promising SSE and RE values obtained reflect that the model is useful in identifying the most contributory factor for students' learning habits during the COVID-19 pandemic.

\section{Conclusion}

This paper presented a study to investigate the contributory factors of students' learning habits during the COVID-19 pandemic using Radial Basis (RBF) network. Vietnamese secondary students' dataset was used in which it composed of a total of 420 respondents. There were fifteen independent variables used as the input for the RBF network and the network was based on the 15-9-1 structure. Based on the result obtained from the experiment, it was observed that the most contributory factor in students' learning habits during the COVID-19 pandemic was the learning hours before the COVID-19 pandemic (Lh_before_Covid). This means that students' learning behaviour before the pandemic was a necessity in maintaining their learning behaviour during the pandemic. It is also concluded that the implementation of the RBF model was fair and effective with the small number of SSE and RE produced from the developed model. On a different side, this study contributes towards the investigation of the contributory factors in students' learning habits during the pandemic. In the future, it is suggested that the exploration of the contributory factors is further investigated as it is important in preparing educational institutions and society for a better learning environment.

\section{Acknowledgements}

This research was supported by Universiti Teknologi MARA Cawangan Melaka under the TEJA Internal Grant Scheme 2020 (GDT2020-36).

\section{References}

1. Jiangfeng, Li. 2017. Analysis of the Impact of Online Courses on the College Student Learning Habit. In Proceeding of the Second International Conference on Mechanical, Control and Computer Engineering.

2. Cakiroglu, U. 2014. Analyzing the Effect of Learning Styles and Study Habits of Distance Learners on Learning Performances: A Case of an Introductory Programming Course. International Review of Research in Open and Distance Learning. 515(4), 161-185.

3. Wang, S., Iwata, J., and Jarrell, D. 2018. Exploring Japanese Students' E-Learning Habits. JALT CALL Journal. 14(3), 211-223.

4. Almaiah, M. A., Al-Khasawneh, A., and Althunibat, A. 2020. Exploring the critical challenges and factors influencing the E-learning system usage during COVID-19 pandemic. Education and Information Technologies. 1, 1-20.

5. Sabri, N., Musa, N. H., Mangshor, N. N. A., Ibrahim, S., and Hamzah, H. H. M. 2020. Student emotion estimation based on facial application in E-learning during COVID-19 pandemic. International Journal of Advanced Trends in Computer Science and Engineering. 9(1.4 Special Issue),576-582. 
6. Urh, M., and Jereb, E. 2014. Learning habits in higher education. In the Proceeding of Procedia-Social and behavioral sciences.

7. Reid, J. M. 1995. Learning styles in the ESL/EFL classroom. Heinle \& Heinle Publishers, International Thomson Publishing Book Distribution Center.

8. Proctor, B. E., Prevatt, F. F., Adams, K. S., Reaser, A., and Petscher, Y. 2006. Study skills profiles of normal-achieving and academically-struggling college students. Journal of College Student Development. 47(1), 37-51.

9. Venu, K., Palanisamy, N., Krishnakumar, B., and Sasipriyaa, N. 2020. Disease Identification in Plant Leaf Using Deep Convolutional Neural Networks. Handbook of Research on Applications and Implementations of Machine Learning Techniques. 46-62.

10. Effendy, N., Ab Aziz, S.H., Kamari, H.M., Zaid, M.H.M., Budak, C.E.A., Shabdin, M.K., Khiri, M.Z.A. and Wahab, S.A.A. 2020. Artificial neural network prediction on ultrasonic performance of bismuth-tellurite glass compositions. Journal of Materials Research and Technology. 9(6), 1408214092.

11. Ahmadian, A.S. 2016. Chapter 6 - Numerical Methods and Procedures. Numerical Models for Submerged Breakwaters, Butterworth-Heinemann. 93-108.

12. Liu, R., He, Y., Zhao, Y., Jiang, X., and Ren, S. 2020. Tunnel construction ventilation frequencycontrol based on radial basis function neural network. Automation in Construction. 118 (103293).

13. Morfidis, K., and Kostinakis, K. 2019. Comparative evaluation of MFP and RBF neural networks' ability for instant estimation of $\mathrm{r} / \mathrm{c}$ buildings' seismic damage level. Engineering Structures. 197,1-19.

14. Kumar, R., Agrawal, H. P., Shah, A., and Bansal, H. O. 2019. Maximum power point tracking in wind energy conversion system using radial basis function based neural network control strategy. Sustainable Energy Technologies and Assessments. 36(100533).

15. Liang, L., Guo, W., Zhang, Y., Zhang, W., Li, L., and Xing, X. 2020. Radial Basis Function Neural Network for prediction of medium-frequency sound absorption coefficient of composite structure opencell aluminum foam. Applied Acoustics. 170 (107505).

16. Ibrahim, S., Kamaruddin, S. A., Mangshor, N. N. A., and Fadzil, A. F. A. 2020. Performance evaluation of multi-layer perceptron (MLP) and radial basis function (RBF): COVID-19 spread and death contributing factors, International Journal of Advanced Trends in Computer Science and Engineering. 9(1.4 Special Issue), 625-631.

17. Ibrahim, S., Kamaruddin, S. A., Sabri, N., Samah, K. A., Noordin, M., and Shari, A. 2020. The influences of global geographical climate towards COVID-19 spread and death. International Journal of Advanced Trends in Computer Science and Engineering. 9(1.4 Special Issue),612-616.

18. Zhang, S., Ng, W. W., Zhang, J., Nugent, C. D., Irvine, N., and Wang, T. 2019. Evaluation of radial basis function neural network minimizing L-GEM for sensor-based activity recognition. Journal of Ambient Intelligence and Humanized Computing. 1-11.

19. Bayram, S., Ocal, M. E., Laptali Oral, E., and Atis, C. D. 2016. Comparison of multi layer perceptron (MLP) and radial basis function (RBF) for construction cost estimation: the case of Turkey. Journal of Civil Engineering and Management. 22(4), 480-490.

20. Trung, T., Hoang, A. D., Nguyen, T. T., Dinh, V. H., Nguyen, Y. C., and Pham, H. H. 2020. Dataset of Vietnamese student's learning habits during COVID-19. Data in Brief. 30(105682).

21. Da Silva, J. L. M., Mendes, F. V., and Ramos, R. V. 2019. Radial basis function network using Lambert-Tsallis Wq function. Physica A: Statistical Mechanics and its Applications. 534(122168). 